\title{
Inventory Management Practices and Cost: Evidence of Selected Small Scale Cosmetics Enterprises in Douala, Littoral Region of Cameroon
}

\author{
Maclean Nkiemboupoh Teno, Roland A Anyingang (Ph.D)*, Takwa Abonwi Chenaa
}

\author{
Department of Business and Management Studies \\ Pan African Institute for Development, West Africa (PAID-WA), Buea \\ Buea, Cameroon
}

\begin{abstract}
This research is necessitated by the fact that inventory forms a large portion of current assets of cosmetics businesses and any inaccuracies in its management might results in a range of problems. Therefore, it is this most essential aspect of organizational life that cosmetics enterprises in Douala might be neglecting and has ignited the need for such an investigation. This study is aimed at assessing the challenges of inventory management practices and its influence on the cost of small scale Cosmetics enterprises in Douala. The hypothesis of this study investigated the relationship between inventory management practices and cost incurred by small scale cosmetics enterprises in Douala. The research design adopted for this study was Ex-post facto research design. A Sample of 30 small scale cosmetic enterprises were drawn using the stratified random Sampling. The instrument used for this study was a well validated structured questionnaire. The alpha Cronbach reliability method was used to test he reliability of the instrument. Ordinary Least Multiple regression statistical technique was used to test the hypothesis of the study. The findings revealed that; there exist a significant and inverse relationship between collaboration with partners and cost of small scale cosmetic enterprises in Douala, a significant and inverse relationship exist between lead time management and cost incurred by small scale cosmetics in Douala. The findings also revealed that there exist a significant relationship between stock control and classification and the cost of small scale cosmetics enterprises in Douala and there exist a significant relationship between stock level management and cost of small scale cosmetics in Douala.Thus the study had made some recommendations to the businesses concerned, to the government through the local councils and the ministry of small and medium size enterprises to close the gap by organizing seminars and training on inventory management amongst others."
\end{abstract}

Keywords: Inventory management, Inventory Management Practices, Inventory cost and Small Scale Cosmetics Businesses.

\section{INTRODUCTION}

Small Enterprises (SEs) occupy a place of strategic importance in developing as well as developed countries owing to its considerable contribution to national income, employment, exports, and entrepreneurship development (Saxena, 2012). At all stages of development, Small Sized Enterprises (SEs) have a meaningful role to play in economic development in general and industrial development in particular (Storey, 1994). In a world of intense competition fueled by globalization, increasing consumer awareness, and technological improvement, organizations that are keen towards large scale success must at all times buildup its service availability as consumers can very easily divert their patronages elsewhere (Sharma, 2009). Despite their significance and the increased efforts to ensure the success of small scale enterprises, the International Labour Organization (2010) estimates that two-thirds of the enterprises were generating incomes equal to or below the minimum wage, a troubling finding that raises lots of questions for the growth of SE's as a solution to the country's poverty and employment problems.

In Cameroon, just like many developing economies, SEs occupy a central place in the economy and play a major role in stimulating growth and development. Abor and Adjasi (2007) articulated that SMEs contribute about 85 per cent of businesses in the country. Small enterprises have been identified as the catalyst for the economic growth of the country as they are a primary source of income and employment (Mensah, 2012). In a developing economy like Cameroon, the share of 
business activity represented by the SE sector has increased considerably over the last decade of the 21st Century (Abor and Adjasi) and play an important role in achieving the Sustainable Development Goals (Appah,2015). The long-term goal is for SEs to maximize their contribution to the country's economic and social development of production, income distribution, employment and the closer integration of women and people in rural areas within the national economy. Given their significance to a nation's economic growth and the role that they play in the fight against poverty, an understanding of the problems which negatively affect these businesses particular small cosmetics enterprises in Douala which are the focus of this paper is a vital first step in managing and avoiding their massive failure.

Baron et al., (2010) suggest that to improve the performance of small businesses, effective inventory management practices need to be adopted. Rajeev (2008) on the other hand proposes that companies should embrace effective inventory management practices to improve their competitiveness in the market. Inventories are essential for keeping the production wheels moving, keep the market going and the distribution system intact. They serve as lubrication and spring for the production and distribution systems of organizations. Inventories make possible the smooth and efficient operation of manufacturing organizations by decoupling individual segments of the total operation. Purchased parts inventory permits activities of the purchasing and supply department personnel to be planned, controlled and concluded somewhat independently of shop-product operations. These inventories allow additional flexibility for suppliers in planning, producing and delivering an order for a given products part. Thus, it represents one of the most important assets that most businesses possess and the turnover of inventory represents one of the primary sources of revenue generation and subsequent earnings for the company (Prempeh, 2016). Consequently, the management of an organization becomes very concerned in inventory stocks are high. There for, it should be managed in order to avail the inventories at right time in right quantity. Inventory can be also viewed as an idle resource which has an economic value. So, better management of the inventories would release capital productively.

It is in this light that Sallemi, (1997) postulated that Management is very critical about any shortage of inventory items required for production. Any increase in the redundancy of machinery or operations due to shortages of inventory may lead to production loss and its associated costs. These two aspects call for continuous inventory control. Inventory control and management not only looks at the physical balance of materials but also at aspects of minimizing the inventory cost. Well and efficiently controlled inventories can contribute to the effective operation of the firm and hence the firms overall profit (Dobler, 2000). Proper management of inventory plays a big role in enabling other operations such as production, purchases, sales, marketing and financial management to be carried out smoothly. Basic challenge however is to determine the inventory level that works most effectively with the operating system or system existing within the organization. At this point, there is no doubt that inventory management enhances performance.

Organizations with high levels of finished goods inventory can offer a wide range of products and make quick delivery from their backyards to the customers. However, while the critical role of inventory management for the survival of an enterprise is recognized in theory, it is not drive in practice in the context of Cameroon SEs. When business strategies are formulated inventory management is generally not handled as a critical issue. Investigating therefore on the relationship between inventory management practices and cost of small scale cosmetics businesses in Douala is therefore of paramount importance.

\section{Hypothesis}

There is no significant relationship between inventory management practices and cost

\section{LITERATURE REVIEW}

Inventory Management plays a pivotal role in the improvement of efficiency and competitiveness of business enterprises. It saves the production wheels moving, keep the market going and the distribution system intact. They serve as lubrication and spring for the production and distribution systems of organizations. Inventories make possible the smooth and efficient operation of manufacturing organizations by decoupling individual segments of the total operation. Purchased parts inventory permits activities of the purchasing and supply department personnel to be planned, controlled and concluded somewhat independently of shop-product operations. These inventories 
allow additional flexibility for suppliers in planning, producing and delivering an order for a given products part. Proper management of inventory plays a big role in enabling other operations such as production, purchases, sales, marketing and financial management to be carried out smoothly (Dobler, 2000). A well and efficiently controlled inventory system can contribute to the effective operation of a firm and hence the firms overall profit (Sople, 2010). Similarly, Chase et al. (2009) showed that inventory control is vital as it holds up money.

Inventory management and control are crucial to a firm because mismanagement of stocks threatens a company's viability (Sprague and Wacker, 1996). Too much inventory consumes physical space, creates a financial burden, and increases the possibility of damage, spoilage, and loss. In this context the lean production principle pioneered by Womack et al. (1990) has been linked to reduced inventories, on the other hand, too little inventory often disrupts manufacturing operations and increase the likelihood of poor customer service. Stock brings with it many costs which have to be considered when setting inventory levels. These include unit cost, ordering costs, carrying cost and stock-out costs (Smith, 2010). It is therefore a prerequisite for business enterprises to embrace effective inventory management practices as a strategy to improve their competitiveness (Rajeev, 2008). Proper inventory management therefore requires the analysis of costs involved in holding too much stock, cost of ordering, cost of running out stock and backorder cost. As Ross et al. (2008) observed, the Economic Order Quantity (EOQ) model is an approach of determining the optimal inventory level that takes into account the inventory carrying costs, stock-out costs and total costs which are helpful in the determination of the appropriate inventory levels to hold.

An ideal inventory levels therefore reduces the cost of possible interruptions or of loss of business because of scarcity of products, reduces supply costs, and protects against price fluctuations. Lazaridis \& Dimitrios (2005) emphasized the significance of firms keeping their inventory at an optimum level by analyzing the relationship between working capital management and corporate profitability and stressed that its mismanagement will lead to excessive tying up of capital at the expense of profitable operations. Supply chain Collaboration has also been considered the driving force behind effective management of inventory as it gives members in the chain up to date information and can reduce management cost if properly managed (Mengue, 2008). He added that a collaborative focus can provide several dividends throughout the supply chain. Supply chain collaboration can positively impact operational effectiveness and efficiency as well as profitability (Cooper and Ellram, 2005, Min and Frank 2005). Five factors are key to successful collaboration: a willingness to innovate and change, understanding the other partner's business, common goals and objectives, appropriate measures and incentives, and information sharing (Frankel, 2002).

Lead time is the amount of time between the placement of an order and the receipts of the goods ordered as stated by Nordas et al., (2006). Active lead time management practice helps to reduce stock out cost living customers satisfied. Suppliers provide an assessment of lead time, but these numbers are not always correct. The differences between your anticipated receipt date and actual receipt date can become expensive from the resulting unplanned overstocks, out of stocks, and deflated consumer opinions. Lead time tracking and lead time forecasting are mission critical to the success of your supply chain. The lead time affects the level of inventory held by businesses (Cachon \& Olivares, 2010). This view is also held by Sander et al. (2010) who asserted that the amount of inventory ordered at particular intervals does affect the replenishment intervals.

In practice, all inventories cannot be measured with equal attention. According to Vilfredo Pareto (1848-1923) Inventory classification is an effective way to manage a large number of items. As a basic methodology, $\mathrm{ABC}$ analysis is widely used for classification of inventory items. ABC Analysis is an inventory control system. The traditional $\mathrm{ABC}$ classification is based on only a single criterion. Each item should receive a treatment corresponding to its class:

A-items should have tight inventory control, more secured storage areas and better sales forecasts; reorders should be frequent, with weekly or even daily reorder; avoiding stock-outs on A-items is a priority

B-items benefit from an intermediate status between A and C; an important aspect of class B is the monitoring of potential evolution toward class A or, in the contrary, toward the class $\mathrm{C}$.

Reordering C-items is made less frequently; a typically inventory policy for $\mathrm{C}$-items consist of having only 1 unit on hand, and of reordering only when an actual purchase is made; this approach leads to 
stock-out situation after each purchase which can be an acceptable situation, as the C-items present both low demand and higher risk of excessive inventory costs.

The results of an $\mathrm{ABC}$ Analysis extend into a number of other inventory control and management processes:

a) Cycle counting: the higher the usage, the more activity an item is likely to have; to ensure accurate record balances, higher priority items are cycle counted more frequently; " $\mathrm{A}$ " items are counted once every quarter; "B" items once every 6 months; and "C" items once every 12 months.

b) Identifying items for potential consignment or vendor stocking: since " $\mathrm{A}$ " items tend to have a greater impact on investment, these would be the best candidates to investigate the potential for alternative stocking arrangements that would reduce investment liability and associated carrying costs.

c) Turnover ratios and associated inventory goals: "A" items will have greater usage than "B" or "C" items, and as a result should have greater turnover ratios; when establishing investment and turnover metrics, inventory data can be segregated by ABC classification, with different targets for each category.

Inventory management is to make decisions concerning the appropriate stock level. There are four main types of stock levels which are: the maximum stock level, minimum stock level, danger level and re-order level. The maximum stock level is the level which stocks is not allowed to go above Narayanappa and Aggarwal, (2013). Minimum stock level refers to the level below which stocks should not normally go down. The Re-Order level is the level at which a company should order more supplies. A fixed re-order level is set for every item of stock. Safety stock is introduced into supply chains to hedge or cater for uncertainty and ensured that customer received the promised service levels Blau et al., (2008).

It is therefore clear that mismanagement of inventory will lead to tying up excess capital at the expense of profitable operations and suggested that managers can create value for their firms by keeping inventory to an optimum level. This is in line with Sushma \& Phubesh (2007) in their study on Consumer Electronics Industry firms established that businesses' inventory management policies had a role to play in their profitability performance. Likewise, Rajeev (2008) evaluate the relationship between inventory management practices and inventory cost established that effective inventory management practices have a positive impact on the inventory performance of businesses and also have an eventual effect on the performance of businesses.

Studies available have not directly examined the impact of supply chain collaboration, lead time management on proper inventory management. Although studies have been carried on stock classification and level and their impact on enterprises, there is still much to be desired especially in small scale businesses. This is evident from the studies that have been mentioned above. The studies also have a favoritism focus on the manufacturing sector than the retail sector. This leaves a gap, showing that there is still much to be desired in this area particularly in Cameroon. Owing to the fact that there is limited literature related to inventory management particularly in Cameroon and that studies elsewhere have not link the above practices on cost reduction, this paper is assumes significance. Therefore the objective of this paper is to bridge this gap by investigating the inventory management practices of small scale cosmetics enterprises in Douala Cameroon and how this affects their performance. The present study further validates, using regression analysis, the impact of the degree of effectiveness of inventory management practices such as collaboration with partners, lead time management, stock classification and control and stock level management on the performance of small scale cosmetics businesses in Douala Littoral Region of Cameroon

\section{Methodology}

The research design adopted for this study was Ex-post facto research design. A sample of 30 small scale cosmetics enterprises in Douala Metropolis were selected using stratified random sampling technique. The main instrument for data collection was a well validated structured questionnaire. The instrument was equally subjected to reliability using Cronbach Alpha reliability coefficient. Data collected was analysed using Ordinary Least Square Multiple Regression Statistical.

\section{Model Specifications}

The model used in this work is proposed by the researchers to test the impact on inventory management on the performance of an organization. The standard states that, inventory management 
is depended on some practices (inputs) and the effectiveness of these inputs contribute to the fulfillment of an organization (output) which intern meets customer's satisfaction. The inputs in the model are lead time, partner's collaboration, stock level management, and Control practice.

Proposed inventory management Model for this study borrows from the EOQ and the ABC analysis. The EOQ introduces us to the notion of cost, lead time and the replenishment of the stock, while the $\mathrm{ABC}$ analysis introduces us to the notions that different products have different value and this determine the amount of stock to be held and the level of control needed to manage inventory judiciously. These two theories are inputs used in the proposed model for this study.

$$
\text { COST }=\mathrm{f}(\mathrm{CWP}, \mathrm{LTM}, \mathrm{SCC}, \mathrm{SLM})
$$

Transforming the model mathematically we have

$$
\operatorname{COST}=\mathrm{a} 0+\mathrm{a} 1 \mathrm{CWP}+\mathrm{a} 2 \mathrm{LTM}+\mathrm{a} 3 \mathrm{SCC}+\mathrm{a} 4 \mathrm{SLM}
$$

Where:

$$
\begin{aligned}
& C W P=\text { collaboration } \text { with partners } \\
& L T M=\text { Lead time management } \\
& S C C=\text { stock classification and control } \\
& S L M=\text { Stock level management } \\
& a 0=\text { regression constant }
\end{aligned}
$$

\section{4. a1, a2,a3 and a4 are Coefficient of the Various pFINDINGS}

\begin{tabular}{|c|c|c|c|c|c|c|}
\hline \multicolumn{7}{|c|}{ Coefficients $^{\mathrm{a}}$} \\
\hline \multirow{2}{*}{\multicolumn{2}{|c|}{ Model }} & \multicolumn{2}{|c|}{ Unstandardized Coefficients } & \multirow{2}{*}{$\begin{array}{l}\text { Standardized Coefficients } \\
\text { Beta }\end{array}$} & & \multirow[t]{2}{*}{ Sig. } \\
\hline & & $\mathrm{B}$ & Std. Error & & & \\
\hline \multirow{5}{*}{1} & (Constant) & 4.386 & 2.014 & & 2.177 & .039 \\
\hline & CWP & -.139 & .175 & -.135 & -.795 & .434 \\
\hline & LTM & -.191 & .082 & -.331 & -2.347 & .027 \\
\hline & SCC & -.343 & .150 & -.413 & -2.284 & .031 \\
\hline & SLM & -.302 & .108 & -.403 & -2.791 & .010 \\
\hline
\end{tabular}

\section{Test of Hypothesis}

The is no significant relationship between inventory management practices and cost. Ordinary Least Square Multiple Regression Statistical technique was used to test this hypothesis. The result is presented in Table 1.

Table1. Regression result of the relationship between inventory management practices and cost in small scale cosmetics enterprises in Douala Littoral Region of Cameroon.

$\mathrm{R}^{2}=0.68$

$\operatorname{Adj} R^{2}=0.63$

$\mathrm{F}=13.55$

The result in Table 1 revealed an $\mathrm{R}^{2}$ value, the coefficient of multiple determinant of 0.68 . This means that 68 per cent changes in the dependent variable cost reduction is cause by changes in collaboration with partners, Lead time management, stock classification and control, and stock level management. This therefore means that the other 32 per cent changes in cost reduction is cause by other variables not shown in the equation but indicated by the error term. The adjusted $\mathrm{R}^{2}$ value of 0.63 implies that the model is 63 per cent goodness fit. The F-value of 13.55 which is significant at 0.05 level of significance means that there exist a significant relationship between the dependent variable of cost reduction and the independent variables of collaboration with partners, Lead time management, stock classification and control, and stock level management. The estimated coefficients for collaboration with partners, Lead time management, stock classification and control, and stock level management are all negative. This means that there exist an inverse relationship between these variables and cost. In order words when these variables increases cost reduces. These results are in order with economic a priori criteria and are all significant at 0.05 level of significance. 
This findings do not collaborate the findings of study carried out by Roumiantsev and Netessine (2005). They investigated the association between inventory management policies and the financial performance of affirm using conventional firm specific variables (inventory levels, margins, and lead times) as explanatory variables and found no evidence that smaller relative levels are associated with financial performance as measured by return on assets. The disparity is as a result of the choice of variables used. Even though adopting the right inventory policies is important for the financial performance of small enterprises, adopting the best inventory management practices is a fundamental and invaluable tool for the success of these enterprises. However, the studies carried out by (Oko, Mgbonyebi and Umeadi (2008); Eneje, Nweze and Udeh (2012); Gruen \& Corsten (2007) \& Zinn \& Liu (2008)) all collaborated the findings of this study. Consequently, good inventory management practices requires that the costs of maintaining certain levels of inventory be effectively analysed as there are costs involved in holding too much stock and there are also costs involved in holding too little stock. Therefore, small enterprises in particular and all enterprises in general should put in place an effective stock management system that minimises inventory cost and ensures reliable sales

\section{Summary of Findings, Conclusion and Policy Recommendations}

\subsection{Summary of Findings}

The study aimed at assessing the inventory management practices and its influence on cost of small scale Cosmetics enterprises in Douala. The hypothesis of the study investigated the relationship between inventory management practices and cost. The research design adopted for this study was the causal comparative design. A Sample of 30 small scale cosmetic enterprises were drawn using the stratified random Sampling. The instrument used for this study was a structured questionnaire. Ordinary least square multiple regression statistical technique was used to test this hypothesis with the use of the Statistical Package for Social Science (SPSS) version 20. The study found out that:

1. There exist a significant relationship between collaboration with partners and cost of small scale cosmetic enterprises in Douala

2. A significant relationship exist between lead time management and cost of small scale cosmetics in Douala

3. There exist a significant relationship between stock control and classification and the cost of small scale cosmetics enterprises in Douala and,

4. There exist a significant relationship between stock level management and cost of small scale cosmetics in Douala

\subsection{Conclusion}

Small scale businesses is the bed rock of most countries around the globe and it can go a long way towards contributing in attaining Sustainable Development Goals 1 (End poverty in all its forms everywhere) and Goal 8 (Promote sustained, inclusive and sustainable economic growth, full and productive employment and decent work for all).Poor inventory management among small scale cosmetics enterprises is obstructing the efforts of the international community to achieve some of the Sustainable Development Goals. Addressing poor inventory management practices on small scale cosmetics enterprise performance is fundamental to creating sustainable livelihoods that can help achieve economic development. Specifically, the findings of the study led us to the conclusion that the type and quality of inventory management practices adopted by small enterprises is fundamental in influencing the financial performance of the enterprises. These practices varies with enterprises and whatever practices are adopted, their proper and effective management is essential for enterprises which intend to register large scale successes.

In the case of small scale enterprises in Douala, the findings show that lead time management when well-handled will significantly reduce cost spent by small scale cosmetics in Douala Also stock control and classification significantly influence cost incurred by small scale cosmetics enterprises in Douala and stock level management has a significant influence on cost incurred by small scale cosmetics in Douala

\subsection{Policy Recommendations}

With the aim to foster economic development in Douala and its environs, this study proposes some measures that constitute effective ways of planning and managing poor inventory management and scenarios in order to mitigate and prevent the recurrent case to take place elsewhere. This study 
suggests that in order to mitigate the prominent and persistent problem of poor inventory management that negatively affect small scale enterprises in Douala. The communal efforts of all stakeholders are highly recommended. This paradigm shift could deviate what has been in place which was gambling with policies and poor planning, especially as stakeholders of inventory management issues wait for a conflicting situation to happen before they begin to sort for mitigation strategies.

Based on the above observations, this study therefore is aimed at proposing eminent recommendations capable of providing lasting solutions to this perennial problem and also to prevent the possibility of new inventory management practices emerging. Recommendations have been made to the various stakeholders on inventory management matters at the micro and macro levels.

$\mathrm{t}$ to improve on the inventory management practices, ordering of goods should be done based on demand forecast, each product item should have a maximum stock level, minimum stock level, reorder and buffer stocks. Here automated systems such as the BAR CODING technology can be put in place and the level of collaboration with members in the supply chain should be very close in other to exchange value information concerning changes in the market place.

To minimize inventory cost through employing proper inventory management practices, it is imperative for the small cosmetic enterprises to know the various cost associated with inventory management for improved performance. This study recommended that the knowledge of these enterprises be enhance by educating them on the various cost associated with inventory management. This can be done by organizing workshops, seminars and talk shows. This will help the small scale enterprises to know the various cost to guard against. Some of the relevant cost to guard on includes; Carrying costs (Cost for holding the inventory over time, cost of money tied up in inventory, obsolescence, insurance, personal property taxes, and storage costs), Procurement costs (Cost of preparing the order, Cost of order transmission, Cost of materials handling or processing at the receiving dock, Price of the goods), Out-of-stock costs (Lost sales cost, Profit immediately foregone, Future profits foregone through loss of goodwill) and Backorder cost (Costs of extra order handling, Additional transportation and handling costs, possibly additional setup costs ) if all these cost are properly managed performance will increase.

\section{REFERENCES}

[1] Association of Certified Chartered Accountant (ACCA) (2010).Financial Management.(2nd ed.): Berkshire: Emile Woolf Publishing Ltd.

[2] Agus, A \& Noor, Z.M (2006). Supply chain management and performance: An Empirical Study. A working paper university of Malaysia.

[3] Ballon R. H., (2004).Business logistics/supply chain management. planning, organizing and Controlling the Supply Chain (5th ed.), New Jersey: Prentice Hall. USA. Pg 326

[4] Bessant, J., Jones, P., \& Lamming, R. (2005).Strategic operations management. Oxford: Elsevier Butterworth-Heinemann.

[5] Bicheno, J. (1996).Supplier partnerships. National institute for manufacturing management, London: Freelance Publishers

[6] Biggart, T.B., \& Gargeya, V.B. (2002).Impact of JIT on inventory to sales ratios. Journal of Industrial Management and Data System. 102(4) [Online]. Available at: <http://www.emeral dinsigh.com/0263-5577.htm>. Accessed: 29/07/2010. p. 197.

[7] Blackstone, J. H. (2001).Theory of constraints - a status report. International Journal of Production Research, 39(6), 1053-1080.

[8] Boysen, N.; Bock, S.; Fliender, M., (2013): Scheduling of inventory releasing jobs to satisfy time-varying demand: an analysis of complexity, Journal of Scheduling, 2 (16), 185-198.

[9] Brigham, E.F \& Gapenski L.C (1993).Intermediate financial management. New York: Dryden Press.

[10] Brownell, J. (2005): Strengthening the Purchase Supplier Partnership. A working paper Cornell

[11] Christopher, M. (2000).The agile supply chain competing in volatile markets. Industrial Marketing Management, 29 (1), 37-44. 
[12] De Leeuw, S., Holweg, M., \& Williams, G. (2011).The impact of decentralized control on firmlevel inventory. International Journal of Physical Distribution \& Logistics Management, 41(5), 435-456.

[13] Disney, S. M. \& Towill, D. R. (2003).The effect of vendor managed inventory dynamics on the bullwhip effect in supply chains. International Journal of Production Economics, 85(2), 199215.

[14] Drury, C. (2004): Management accounting. (6th Ed.). London: Thomson.

[15] Dubelaar, C., Chow, G., \& Larson, P.D. (2000). Relationships between inventory, sales and service in a retail chain store operation. International Journal of physical Distribution Management. [Online]. Available at: <http://www.emerald-library.com>. Accessed: 02/010/2012 pp. 96-101.

[16] Dubelaar, Chow \& Larson, H. (2000).An econometric analysis of inventory turnover performance in retail services. Management Science, 5,181-194.

[17] Dumas, C. (2008).Effective inventory management in small to medium-sized enterprises.MBA. Mini-dissertation, Potchefstroom: North-West University.

[18] Dumas, C. (2008).Effective inventory management in small to medium-sized enterprises. New Jersey: Prentice Hall

[19] Eckert, S.G (2007).Inventory management and its effects on customer satisfaction. Journal of Public Policy,1(3), 37-43

[20] Eneje, C., Nweze, A. \&Udeh, A. (2012). Effect of efficient inventory management on profitability: evidence from selected brewery firms in Nigeria, International Journal of Current Research,. 4, 350-354).

[21] Flores, L. A. F. S. \& Primo, M. A. M. (2008).Failure recovery management in performance of logistics services in a B2B Context: A Case Study Using the 3PL Perspective. Journal of Operations and Supply Chain Management, 1(1), 29-40.

[22] Fred, O. N (2013). Challenges facing micro and small enterprises in inventory management in Kisii Town, Kenya, Journal of Business and Management, 36, 28-36

[23] Gaither, N. \& Frazier, G (1999).Production and operations management. Illinois: Thomson South-Western, USA.

[24] Garrison, G\& Noreen, H. (2003). Inventory behaviour and efficacy of credit control.Anvesak,2 (II), 168-175.

[25] Garrison, R.H., Noreen E.W., \& Seal, W. (2003).Management accounting. London: McGrawHill.

[26] Gourdin, K. N., (2001), Global logistics management. A competitive advantage for the new millennium. New York: Blackwell Business.

[27] International Labour Organization (ILO) (2010). Voucher program for training and business development services in Kenya micro and small enterprise training and technology project. Accessed at http://www.ilo.org/public/english/

[28] Jader, J. (2012).Lead time reduction: Improving the customer's service experience. Retrieved on May $23^{\text {rd }}, 2016$ from www.eneneye/tt-983.com

[29] Koh, C., Demirbag, M., Tatoglou ,E, \& Zaim, S. (2007). The impact of supply chain practices on performance on SMES. Industrial Management \& Data systems 107(1),103 -240)

[30] Kolitz, D.L., Quinn, A.B., \& McAllister, C. (2009).A concepts based introduction to financial accounting. (4th Ed.). Lansdowne: Juta. Price Waterhouse Coopers. (2009). Inventories, 22 October 2009. Available at: 〈http://pwcinform.pwc.com>. Accessed: 27/06/2010. p. 1-4

[31] Kothari, Y. (1992). The effect of inventory management on profitability of cement manufacturing companies in Kenya: A case study of listed cement manufacturing companies in Kenya. International Journal of Management and Commerce Innovations, 3(2) 111-119.

[32] Lee, H. L.; Padmanabhan, V. \& Whang, S. (1997a). The bullwhip effect in supply chains, Sloan Management Review, 66, 93-102.

[33] Lee, H. L.; Padmanabhan, V. \& Whang, S. (1997).Information distortion in a supply chain: The bullwhip effect .Management Science, 43 (4) 546-558. 
Inventory Management Practices and Cost: Evidence of Selected Small Scale Cosmetics Enterprises in Douala, Littoral Region of Cameroon

[34] Loughrim, M. (2008). Lean thinking and vendor managed inventory. Retrieved on June 10, 2015 from www.universityofliverpool.com

[35] Lysons, K \& Gillingham, M. (2003). Purchasing and supply chain management. London: Prentice Hall

[36] Magad, R\& Amos, H (1989).On the relationship between inventory and financial performance in manufacturing. International Journal of Operations \& Production Management, 29 (8)789-806.

[37] Okoh, L. Mgbonyebi, D. C. \& Umeadi, A. (2008).Impact of inventory control in enhancing business growth in Nigeria. International Journal of Investment and Finance 1(2) 55-63.

[38] Peter. T \& Robinsons, Y (2006).Inventory management in India. Bombay: Allied Publishers,

[39] Santos, R. F.; Marins, F. A. S. \& Moellmann, A. H. (2007). A real application of theory of constraints to supply chain management. Texas: Prentice Hall

[40] Saxena, V.D. (2012). Internationalization of SMEs n India: Opportunities and challenges. South Asian Journal of Marketing and Management Research, 12(9), 219-228.

[41] Sekaran, U. (2003). Research methods for business: A skill building approach, $4^{\text {th }} \mathrm{ed}$. Singapore: John Wiley \& Sons.

[42] Sharma, J. K (2009).Operations research: Theory and applications, 4th ed., New Delhi: Macmillan Publishers.

[43] Srinivasan, M. M.; Srinivasan, T. \& Choi, E. W. (2005).Build and Manage a lean supply chain. Industrial Management, 47 (5) 20-25.

[44] Starr, G\& Miller, H. (1962). Effect of efficient inventory management on profitability: Evidence from selected brewery firms in Nigeria. International Journal.

[45] Taylor, D. A. (2004).Supply chains: A manager's guide. New York: Pearson Education, Inc

[46] Wang, G.; Huang, S. H. \& Dismukes, J. P. (2004).Product-driven supply chain selection using integrated multi-criteria decision-making methodology. International Journal of Production Economics, 91 (1)1-15.

[47] Waters-Fuller, N. (1996). The benefits and costs of JIT sourcing: A study of Scottish suppliers. International Journal of Physical Distribution and Logistics Management, 26(4):35-50. 